\title{
Polypropylene Materials for Sewerage \& Drainage Pipes with Reduced Energy and Carbon Footprints
}

Jeroen Wassenaar

Total Research \& Technology Feluy, B-7181 Seneffe, Belgium

\begin{abstract}
Driven by a growing global conscience about our influence on the planet's current and future climate and the scarcity of resources to satisfy a growing global population, product design that takes into account the product's impact on both these factors is becoming increasingly important. In this paper a life cycle analysis is presented that looks specifically at two recently developed PP materials for S\&D pipes, PP-MD and PP-HM, that have been designed to lower the energy and carbon footprint of the resulting pipes. The LCA focuses on plain wall S\&D pipes with a minimum ring stiffness $\mathrm{SN}>8 \mathrm{kN} / \mathrm{m}^{2}$ and pipe diameters between 110 and $800 \mathrm{~mm}$. The NRED and GWP of these new PP materials are compared to pipes based on conventional PP-B and concrete. It was found that PP-MD is able to provide the lowest GWP of all materials investigated and the lowest NRED of all plastic materials. PP-HM is able to lower the GWP and NRED compared to PP-B by 7\% and 9\%, respectively. Comparison of the results from this study to existing LCA's on PP-B and concrete pipes, demonstrates a very good agreement thus underlining its accuracy and significance.
\end{abstract}

Key words: Life cycle analysis, sewerage \& drainage pipes, carbon footprint, polypropylene, mineral modified pipe.

\section{Introduction}

The reduction of energy consumption and GHG emissions has emerged as a key priority at the outset of this century and is making its way currently into legislation, thus directing new product development towards ecodesign through green procurement incentives. Green public procurement has already been introduced in EU directives since 2004 but is recently being increasingly adopted by public authorities throughout its member states [1].

For the pipe industry and S\&D pipes in particular, which relies heavily on public funding for infrastructure projects this also results in an increasing awareness about the environmental impact of their products. Accordingly, industry associations such as TEPPFA and CPSA have commissioned LCA's on various pipe designs and published their findings in EPD's [2, 3]. Moreover, several academic studies exist on S\&D pipes of varying materials, designs, and diameters [4-6].

Corresponding author: Jeroen Wassenaar, Ph.D., main research field: polymer science.
In comparison to concrete and plastics like PVC and HDPE, the use of PP for the manufacture of S\&D pipes is more recent. Accordingly, innovation activity in terms of new pipe designs and PP resins dedicated to this application is relatively high. Two examples of such innovations are S\&D pipes based on high modulus propylene block copolymers (PP-HM) and mineral modified polypropylene (PP-MD). In the first example the high stiffness of PP-HM allows reducing the wall thickness of plain wall pipes and thus less material needs to be used per unit of length of pipe [7]. PP-MD is a mineral filled compound generally composed of a PP filled with $\mathrm{CaCO}_{3}$ up to $50 \mathrm{wt} . \%$ [8]. This compound displays increased stiffness as well and likewise results in lower wall thickness and lower resource consumption. To the best of our knowledge, PP-HM and PP-MD materials have not yet been included in existing LCA studies on S\&D pipes.

The objective of this study is to evaluate the environmental impact in terms of GWP and NRED, of S\&D pipes based on PP-MD and PP-HM, compared to standard PP-B and non-plastic (concrete) materials. 


\section{Nomenclature}

LCA: Life cycle analysis.

GWP: Greenhouse warming potential.

GHG: Greenhouse gas.

NRED: Non-renewable energy demand.

S\&D: Sewerage \& drainage.

PP: Polypropylene.

PP-B: Propylene block copolymer.

PP-HM: High modulus propylene block copolymer.

PP-MD: Mineral modified polypropylene.

PVC: Polyvinyl chloride.

DEFRA: Department for environment, food and rural affairs (UK).

EPD: Environmental product declaration.

TEPFA: The European plastic pipes and fittings association.

CPSA: Concrete pipeline system association.

\section{Material and Methods}

\subsection{LCA Methodology}

This study has been conducted according to the international ISO 14020 and 14021 standards governing environmental claims, particularly their accuracy. The compliance of the life cycle analysis with these standards has been verified by an external independent auditor. GWP and NRED have been selected as the impact categories to be reported.

\subsection{Functional Unit (fu) Definition}

The functional unit considered in this study is: $1 \mathrm{~m}$ of installed plain wall pipe with a ring stiffness $\mathrm{SN}$ of $>8 \mathrm{kN} / \mathrm{m}^{2}$. The base case will consider a DN/OD of $250 \mathrm{~mm}$ for plastic pipes and the closest equivalent concrete pipe size (DN/ID $225 \mathrm{~mm}$ ). A sensitivity analysis will evaluate the influence of pipe diameter.

\subsection{Life Cycle Stages, System Boundaries \& Data Sources}

The life cycle stages considered as well as included and excluded processes and materials are listed in Table 1.

During the production of raw materials we consider the production and internal non renewable energy content of plastic materials according to the Eco-Profiles by Plastics Europe [9]. GHG emissions are given as the total GHG emitted during the production (from crude oil) of plastic materials according to the Eco-Profiles by Plastics Europe. For $\mathrm{CaCO}_{3}$, the values provided in the LCI established by IMA Europe are used [10]. For unreinforced concrete, GWP and NRED data are based on the values for precast concrete mix 1 provided by the Portland Cement Association [11]. In this case the impact for production of raw materials includes their transport and transformation. For reinforced concrete, data are used from the study by Struble \& Godfrey [12]. NRED

Table 1 Summary of life cycle stages and boundary conditions.

\begin{tabular}{|l|l|l|}
\hline Stage & Included in the analysis & Excluded \\
\hline Production of raw materials & Main thermoplastic and mineral materials & $\begin{array}{l}\text { Pigments, antioxidants, UV stabilizers, elastomeric } \\
\text { rings for push-fit sockets, manholes, etc. }\end{array}$ \\
\hline Transport of raw materials & $\begin{array}{l}\text { One way transport of raw materials to pipe } \\
\text { manufacturer }\end{array}$ & Pipe and raw material handling, storage \\
\hline Transformation & Extrusion process & $\begin{array}{l}\text { Delivery of pipes from manufacturer to trench. } \\
\text { Empty return of truck. }\end{array}$ \\
\hline Pipe transport & $\begin{array}{l}\text { Ancillary materials for installation; mechanical } \\
\text { energy of machinery to dig, backfill, and compact } \\
\text { trench; waste generated on the building site }\end{array}$ & \\
\hline Pipe installation & Not included & - \\
\hline Use & Not included & - \\
\hline End of life &
\end{tabular}


and GWP of all raw materials considered are summarized in Table 2.

For the transport of raw materials we consider the transport by 33t truck of polymers and minerals from the raw material supplier to pipe producer. For the transport of such bulk materials we consider only one-way transport as logistics companies optimize their routes to avoid empty returns. Therefore, the return journey falls outside the boundary conditions of this LCA. The loading percentage of the truck depends on the bulk density of the product, resulting in the following load percentages: PP (76\%), $\mathrm{CaCO}_{3}$ (100\%). GHG emissions and NRED are calculated based on DEFRA carbon conversion factors [13]. The average distance is estimated at $450 \mathrm{~km}$ by truck.

In the transformation phase, which consists of extruding the pipe, the energy consumption is estimated based on average extrusion energies for thermoplastic materials [14]. The associated GHG emissions are calculated based on electrical energy in Europe (EU average) [15].

The transport of pipes is treated similarly to the transport of raw materials described above; however, in this case we also consider the empty return and an average distance of $460 \mathrm{~km}$ in line with the LCA by Cowle et al. [4]. The weight and loading percentage of a "full truck" is calculated based on the length of pipe that can fit into a $13.6 \mathrm{~m}$ trailer multiplied by its weight per meter, provided it does not exceed $33 \mathrm{t}$ in which case the loading percentage is $100 \%$.

GWP and NRED associated with pipe installation for DN/OD $250 \mathrm{~mm}$ S\&D pipes are based on the data provided in the TEPPFA EPD of PVC-U solid wall sewer pipe systems [16]. For other outside diameters the values have been adapted by assuming a linear dependence.

Polyolefin based S\&D pipes have an estimated useful lifetime of at least 100 years [17, 18]. The environmental impact in terms of GWP and NRED of the use phase has been shown to be negligible by previous LCA's commissioned by TEPPFA and is therefore excluded.

End of life treatment is not considered as $>95 \%$ of the pipe systems are left in the ground after their useful life and will therefore not impact the energy and carbon footprint [16].

\subsection{Systems Description}

The environmental impact of S\&D pipes is related to the amount and type of material of the functional unit considered. The dimensions and weights per linear meter of the pipes considered in this study are listed in Table 3.

For the plastic materials, dimensions were taken from the respective European standards quoted in the table. The weight per meter was calculated by multiplying the corresponding material volume with its density. The following densities are used: PP-HM/PP-B (0.9 g/ $\left.\mathrm{cm}^{3}\right)$. For PP-MD the density will depend on the filler level and type. In this study we consider $\mathrm{CaCO}_{3}$ as mineral filler at a level of $50 \mathrm{wt} . \%$. This provides a material density for PP-MD of 1.36 $\mathrm{g} / \mathrm{cm}^{3}$ according to the linear rule of mixtures in filled thermoplastics [19]. It should be noted that only PP base resins with a tailored molecular design are able to accept filler levels up to $50 \mathrm{wt}$ \% whilst still providing a fully homogeneously mixed compound under commercially relevant pipe extrusion conditions. One

Table 2 NRED and GWP per kg of materials considered in this study.

\begin{tabular}{llll}
\hline Material & $\begin{array}{l}\text { NRED } \\
(\mathrm{MJ} / \mathrm{kg})\end{array}$ & $\begin{array}{l}\mathrm{GWP} \\
(\mathrm{kg} \mathrm{CO} \mathrm{eq} / \mathrm{kg})\end{array}$ & Source reference \\
\hline $\mathrm{PP}$ & 77.1 & 1.63 & {$[9]$} \\
$\mathrm{CaCO}_{3}$ & 0.74 & 0.0396 & {$[10]$} \\
Concrete (Precast Mix 1) & 1.38 & 0.214 & {$[11]$} \\
Reinforced concrete & 2.87 & 0.204 & {$[12]$} \\
\hline
\end{tabular}


Table 3 Dimensions and weights of S\&D pipes with $\mathrm{SN}>8 \mathrm{kN} / \mathrm{m}^{2}$ evaluated in this study.

\begin{tabular}{|c|c|c|c|c|c|c|}
\hline Material & Norm & $\begin{array}{l}\mathrm{DN} \\
(\mathrm{mm})\end{array}$ & Inside Diameter (mm) & Outside Diameter (mm) & Wall thickness (mm) & Weight $(\mathrm{kg} / \mathrm{m})$ \\
\hline \multirow{4}{*}{ PP-MD } & \multirow{4}{*}{$\begin{array}{l}\text { EN 14758-1 } \\
\text { [8] }\end{array}$} & 110 & 103.2 & 110 & 3.4 & 1.5 \\
\hline & & 250 & 234.6 & 250 & 7.7 & 8.0 \\
\hline & & 400 & 375.4 & 400 & 12.3 & 20.3 \\
\hline & & 800 & 751.0 & 800 & 24.5 & 81.0 \\
\hline \multirow{4}{*}{ PP-HM } & \multirow{4}{*}{$\begin{array}{l}\text { EN 1852-1 } \\
\text { [7] }\end{array}$} & 110 & 102.4 & 110 & 3.8 & 1.2 \\
\hline & & 250 & 232.8 & 250 & 8.6 & 5.9 \\
\hline & & 400 & 372.6 & 400 & 13.7 & 15.1 \\
\hline & & 800 & 745.2 & 800 & 27.4 & 60.2 \\
\hline \multirow{4}{*}{ PP-B } & \multirow{4}{*}{$\begin{array}{l}\text { EN 1852-1 } \\
\text { [7] }\end{array}$} & 110 & 101.6 & 110 & 4.2 & 1.3 \\
\hline & & 250 & 230.8 & 250 & 9.6 & 6.6 \\
\hline & & 400 & 369.4 & 400 & 15.3 & 16.7 \\
\hline & & 800 & 738.8 & 800 & 30.6 & 66.9 \\
\hline \multirow{3}{*}{ Concrete } & \multirow{3}{*}{$\begin{array}{l}\text { EN } 1916 \\
{[21]}\end{array}$} & 225 & 225 & 305 & 40.0 & 97.6 \\
\hline & & 375 & 375 & 490 & 57.5 & 204.0 \\
\hline & & 750 & 750 & 910 & 80.0 & 576.0 \\
\hline
\end{tabular}

such a resin is polypropylene homopolymer PPH 1060, commercially available through Total Refining \& Chemicals [20].

For concrete pipes the nominal diameter is not given as the outside diameter like for plastic pipes, but instead as the inside diameter of the pipe. Also given the significantly higher wall thickness, we have attempted in this study to choose concrete pipe dimensions that feature an as close as possible match with the inside diameter of the corresponding plastic pipe. Pipe dimensions and weights are based on commonly commercially available precast concrete pipes in accordance with EN 1916 [21]. According to best practices, concrete pipes with DN up to 675 are manufactured from unreinforced concrete, and from DN 750 upwards made from reinforced concrete. Finally, the smallest commercially available concrete S\&D pipe has DN 225, so there is no comparative example to plastic pipes with DN 110.

\section{Results \& Discussion}

\subsection{Base Case: DN/OD 250}

As base case scenario an outside diameter of DN/OD $250 \mathrm{~mm}$ was chosen for plastic pipes and for concrete the closest match is a DN/ID of $225 \mathrm{~mm}$, which is just slightly smaller compared to the plastic pipes (Table 3). The ring stiffness of all these pipe designs is $>8 \mathrm{kN} / \mathrm{m}^{2}$ and one can consider that all designs could compete for the same type of S\&D application. It should be noted that despite equivalent ring stiffness, other properties such as impact resistance and chemical resistance are not the same. The results of the LCA in terms of NRED and GWP are depicted in Figs. 1 and 2, respectively.

The conventional PP-B pipe, which has been treated in previous LCA assessments [23], displays the highest NRED. PP-HM provides a NRED, which is $9 \%$ lower compared to PP-B. A more significant decrease (32\%) of the NRED is obtained with the PP-MD pipe. Finally, concrete pipes exhibit the lowest NRED.

For the plastic pipes the largest contributor to NRED is associated with the internal energy component of the raw material, i.e. energy still contained in the product which will not be released unless incinerated. PP-HM provides a higher stiffness compared to PP-B, allowing the reduction of pipe wall thickness. Therefore less PP is used per meter, resulting in a lower NRED. The same rationale is valid for the lower NRED in the case of PP-MD. As it is contains $50 \%$ of a mineral filler - having no internal energy component - it exhibits the lowest NRED for 


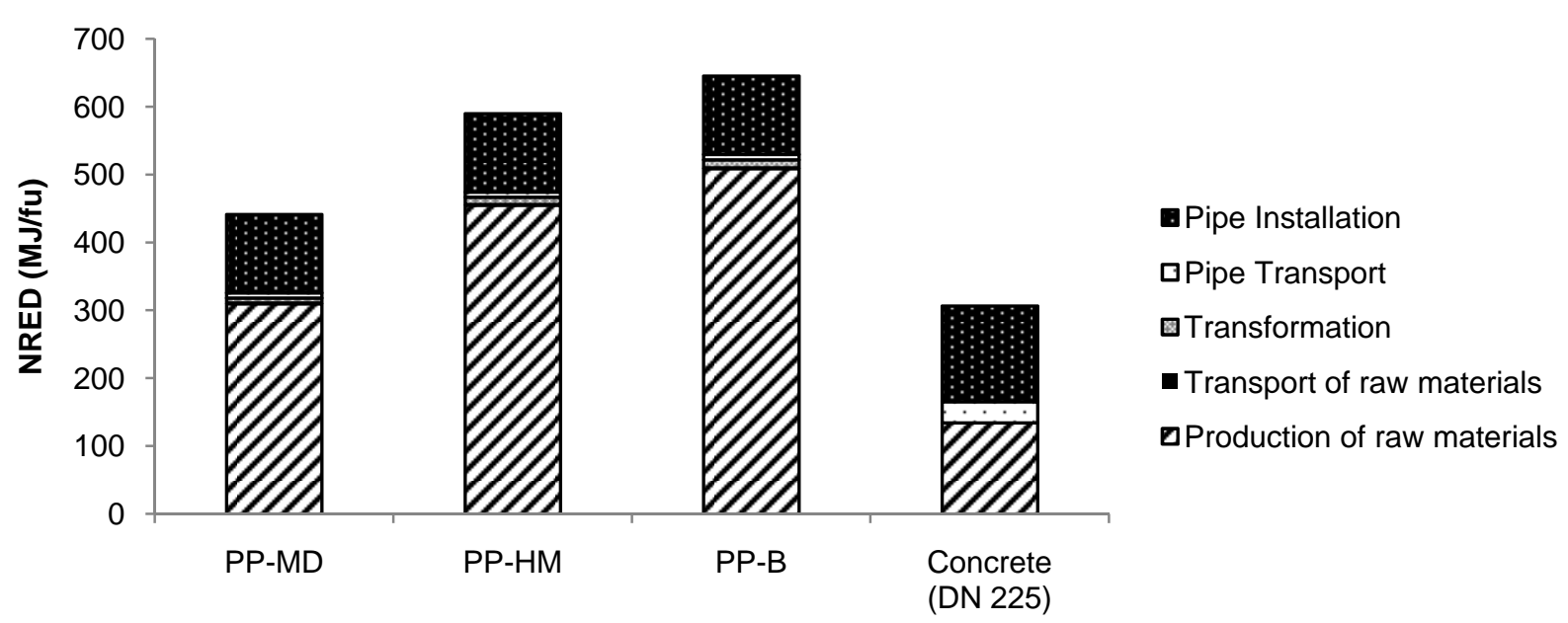

Fig. 1 NRED for $1 \mathrm{~m}$ of installed plain wall S\&D pipe with DN/OD $250 \mathrm{~mm}$ and a ring stiffness SN $>8 \mathrm{kN} / \mathrm{m}^{2}$. In case of concrete DN/ID 225 is used.

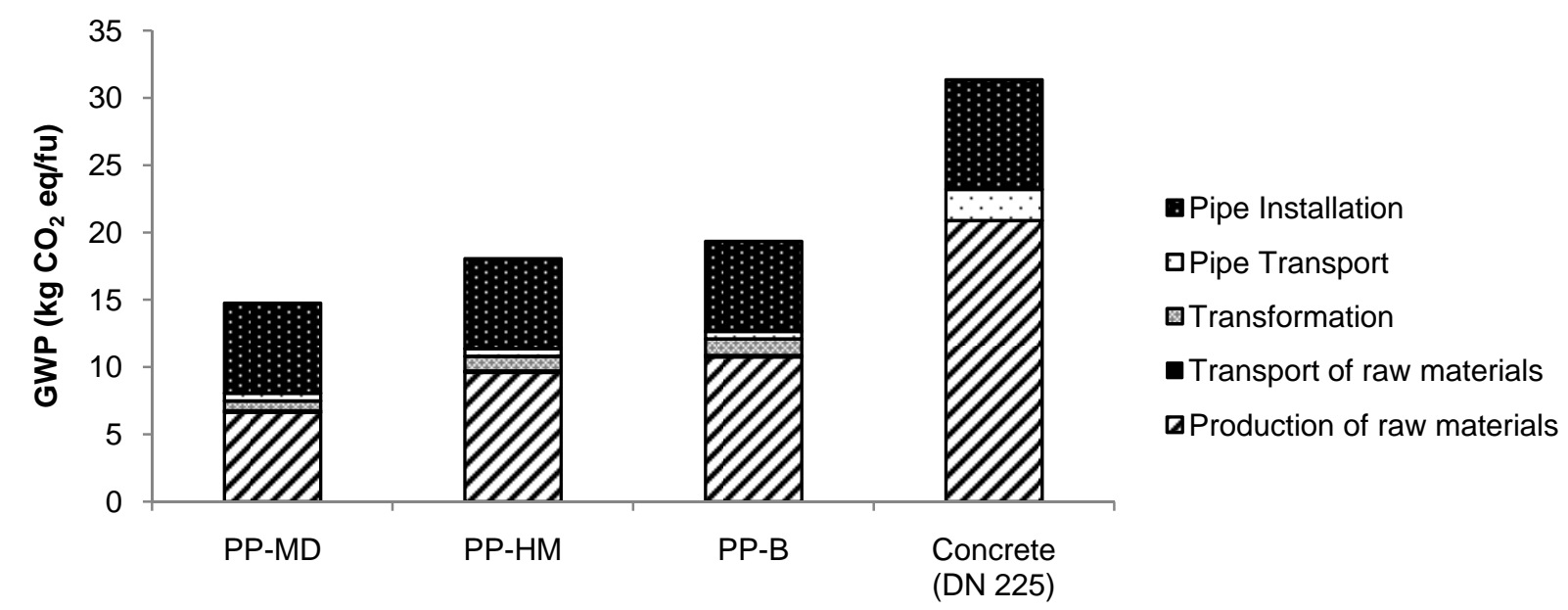

Fig. 2 GWP for $1 \mathrm{~m}$ of installed plain wall S\&D pipe with DN/OD $250 \mathrm{~mm}$ and a ring stiffness SN $>8 \mathrm{kN} / \mathrm{m}^{2}$. In case of concrete DN/ID 225 is used.

PP pipes. Concrete also does not have any internal energy component and displays consequently the lowest raw material impact. The NRED related to transport and installation of the pipe is roughly equal for the plastic pipes as they feature the same OD and similar weight. For concrete pipes on the other hand these stages become the dominant contributor to its NRED due to the higher weight per meter and larger OD. Transport of raw materials and pipe extrusion play a very minor role in the NRED of plastic pipes.

The picture is rather different when the GWP of the different pipe materials is considered. Here we observe the lowest impact for PP-based pipes and the concrete pipe has the highest GWP. One of the main reasons for this is that for GWP the internal energy component is not considered. Only if the pipes would be burned at the end of their life, this internal energy would be transformed into GHG emissions. However, it is known that $>95 \%$ of pipes is left in the ground at the end of their useful lifetime and therefore their internal energy is not released [16, 22]. On the contrary, for GWP energy intensive processes in the conversion of resources into useful raw materials play a much more important role (see Table 2). An example is the heat required in the drying of precast cement. 
In light of these considerations, the lower weight PP-HM results in a lower GWP of these pipes compared to PP-B. The PP-MD pipe is not the lightest but the very low inherent GWP of $\mathrm{CaCO}_{3}$ provides it with the lowest GWP in this study. The high weight per $\mathrm{m}$ of pipe for concrete makes it the material with the highest GWP. Compared to NRED, the contribution of transformation, transport, and installation of plastic pipes to the GWP is more important.

\subsection{Sensitivity Analysis: Pipe Diameter}

In order to assess the influence of pipe diameter on the relative ranking of the pipe materials, we have conducted LCA's for three additional pipe diameters: DN/OD 110, 400 and $800 \mathrm{~mm}$. As pipes with diameters above $699 \mathrm{~mm}$ represent less than $1 \%$ of the total installed S\&D pipe length in Europe [23], we did not aim to look into even larger pipes.

In terms of NRED the ranking of materials established for DN/OD $250 \mathrm{~mm}$ is the same for all diameters investigated (Fig. 3). However, relative differences are more pronounced for larger diameters as the raw material component becomes more important.

\subsection{Comparison to Previous LCA's on S\&D Pipes}

A comparison between different LCA's is generally difficult as the scope and assumptions made are rarely the same. Nevertheless, it can be of interest to look at a rough comparison to evaluate whether the orders of magnitude of the impacts are in the same range. For this purpose we compare the results of the current study in terms of GWP for PP-B pipes with those from the one commissioned by TEPPFA on DN/OD $315 \mathrm{~mm}$ PP pipes [23]. We can compare our results on DN/OD $250 \mathrm{~mm}$ pipes by inferring the GWP at DN/OD $315 \mathrm{~mm}$ from the pipe diameter sensitivity analysis via second order polynomial regression. For GWP we obtain in that case $28.3 \mathrm{~kg} \mathrm{CO}_{2}$ eq. vs. 33.9 $\mathrm{kg} \mathrm{CO}_{2}$ eq. per functional unit as defined in this study. This difference can be explained by the release of a new eco profile for PP by Plastics Europe that has revised GWP 18.7\% lower compared to the 2008 version [9].

For concrete pipes the results of the current study may be compared to the CPSA cradle-to-gate analysis [3]. For a DN/ID $750 \mathrm{~mm}$ we find a GWP of $117.6 \mathrm{~kg}$ $\mathrm{CO}_{2}$ eq. vs. $112.8 \mathrm{~kg} \mathrm{CO}$ eq. per functional unit $(1 \mathrm{~m}$ of pipe cradle-to-gate). A very good agreement considering that different data sources were used.

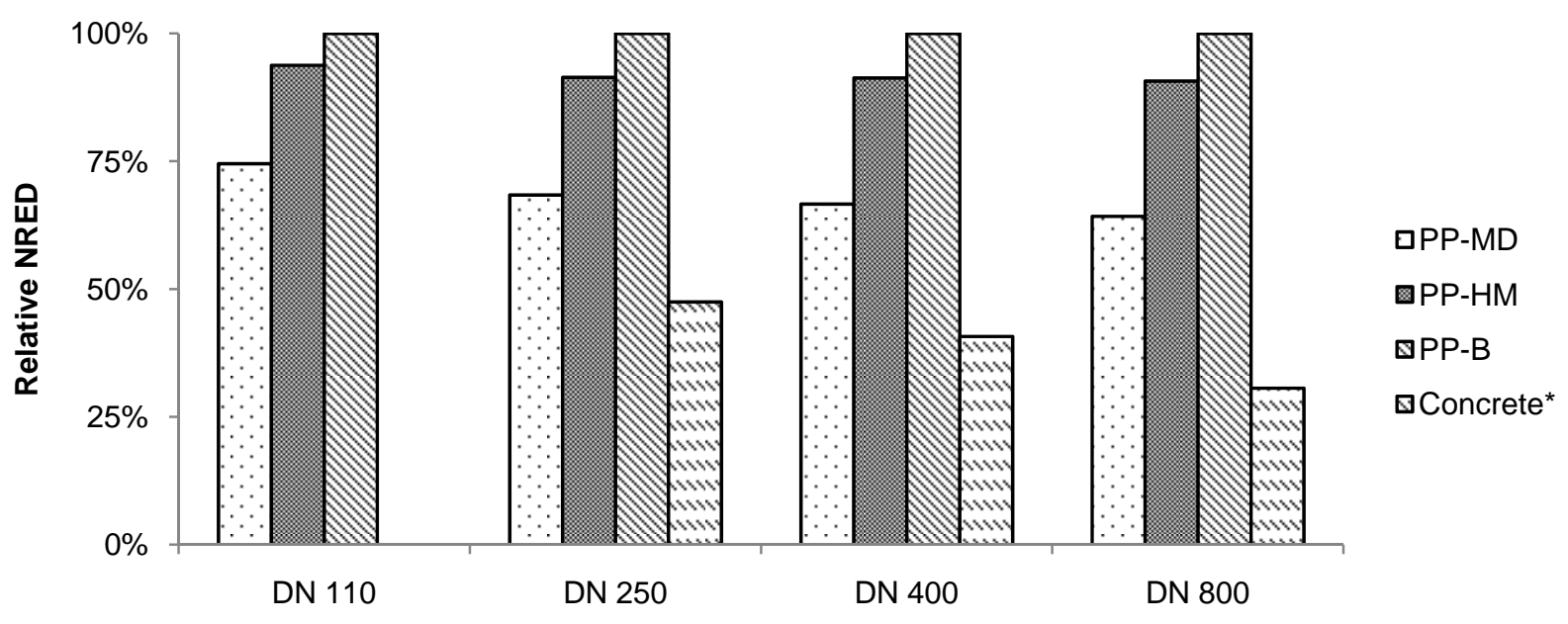

Fig. 3 Relative NRED for $1 \mathrm{~m}$ of installed plain wall S\&D pipe with a ring stiffness $\mathrm{SN}>\mathbf{8} \mathrm{kN} / \mathrm{m}^{2}$ and varying pipe diameter. DN/OD is given for plastic materials. * In case of concrete the closest available size based on inside diameter is chosen (see Table 3). 


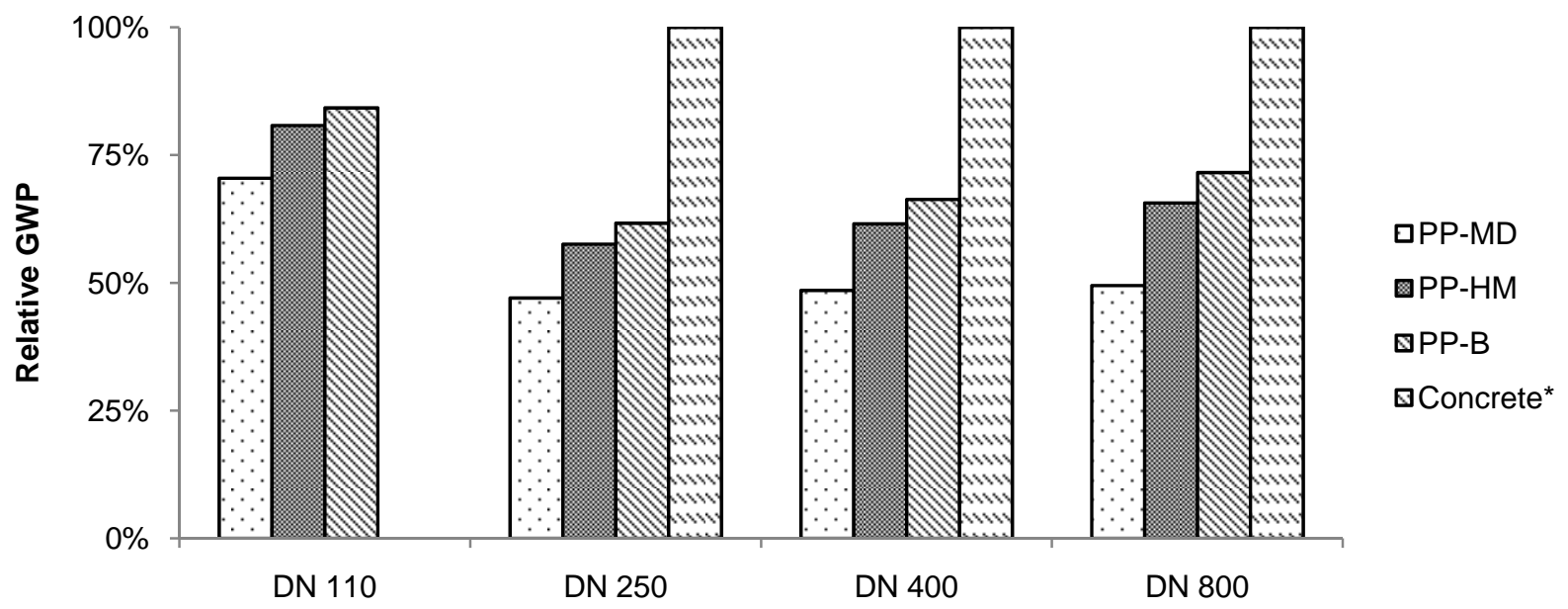

Fig. 4 Relative GWP for $1 \mathrm{~m}$ of installed plain wall S\&D pipe with a ring stiffness $\mathrm{SN}>8 \mathrm{kN} / \mathrm{m}^{2}$ and varying pipe diameter. DN/OD is given for plastic materials. * In case of concrete the closest available size based on inside diameter is chosen (see Table 3).

In contrast, when looking at the LCA of wastewater pipes based on PVC, ductile iron, cast iron, HDPE, concrete, and reinforced concrete reported by Du et al. [5], their conclusions are in stark contrast with our findings as they conclude that unreinforced concrete has the lowest GWP across pipe sizes from ID 102-1,219 mm. It should be noted though that their calculation of GWP is based on a direct conversion from the embodied energy, which is not in line with current best practices in LCA. Therefore, their GWP ranking should be rather viewed as ranking in NRED in which case we arrive at a similar final conclusion.

\section{Conclusions}

In conclusion this study has shown that advances in raw material development for PP S\&D pipes have resulted in new pipe designs that have reduced energy and carbon footprints. PP-MD pipes display the lowest GWP of all materials and over all dimensions investigated, providing a decrease of $24 \%$ vs. conventional PP-B. PP-HM pipes provide a more modest decrease of $7 \%$. Concrete pipes continue to display the lowest NRED but PP-MD is able to close the gap significantly compared to other plastic pipe materials.

The comparison of this study to other LCA's for
PP-B and concrete, allows us to conclude that the findings of this study are in very good agreement with previous studies in the literature. Therefore, the GWP and NRED for PP-MD and PP-HM pipes reported here and that have not been studied before, can be deemed accurate.

\section{References}

[1] European Commission. "Green Public Procurement." Accessed December 19, 2016. http://ec.europa.eu/environment/gpp.

[2] The European Plastic Pipes and Fittings Association. "Environmental Product Declaration." Accessed December 19, 2016. http://www.teppfa.eu/epdoverview.

[3] Jones, K., Olgun, M., and Israfilof, Z. 2010. PAS 2050 Partial Life Cycle-Cradle-to-Gate Analysis for Concrete Pipeline, Manhole Ring and Cover Slab. Concrete Pipeline System Association. Accessed December 19, 2016.

http://www.concretepipes.co.uk/uploads/downloads/Conc rete_Pipeline_PAS_2050_Footprint_report_Nov_2010.pd f.

[4] Cowle, M., Samaras, V., and Rauen, W. B. 2012. “A Comparitive Analysis of the Carbon Footprint of Large Diameter Concrete and HDPE Pipes.” In Proceedings of the 17th Plastic Pipes Conference PPXVII.

[5] Du, F., Woods, G. J., Kang, D., Lansey, K. E., and Arnold, R. G. 2013. "Life Cycle Analysis for Water and Wastewater Pipe Materials.” Journal of Environmental Engineering (May): 703-11.

[6] Kim, D., Yi, S., and Lee, W. 2012. "Life Cycle 
Assessment of Sewer System: Comparison of Pipe Materials.” In Proceedings of the 2012 World Congress on Advances in Civil, Environmental, and Materials Research (ACEM'12), 2963-75.

[7] European Standard. May 2009. "EN 1852-1: Plastics Piping Systems for Non-pressure Underground Drainage and Sewerage Polypropylene (PP), Part 1: Specifications for Pipes, Fittings and the System."

[8] European Standard. May 2012. "EN 14758-1: Plastics Piping Systems for Non-pressure underground Drainage and Sewerage, Polypropylene with Mineral Modifiers (PP-MD), Part 1: Specifications for Pipes, Fittings and the System.”

[9] Plastics Europe. 2014. "Eco-Profiles and Environmental Product Declarations of the European Plastics Manufacturers: Polypropylene (PP).” Accessed December 19, 2016. http://www.plasticseurope.org/plastics-sustainability-140 17/eco-profiles.aspx.

[10] "Life Cycle Inventory (LCI) from Industrial Minerals Association (IMA-Europe): CaCO3 >63 $\mu \mathrm{m}$.” March 2013. Accessed December 19, 2016. http://www.ima-europe.eu/sites/ima-europe.eu/files/publi cations/2013\%2003\%2001_IMA\%20LCI\%20assumption s\%20\%2B\%20results_External_version\%202.pdf.

[11] Marceau, M. L., Nisbet, M. A., and VanGeem, M. G. 2007. "Life Cycle Inventory of Portland Cement Concrete.” Portland Cement Association. Accessed December 19, 2016. http://www.nrmca.org/taskforce/item_2_talkingpoints/sus tainability/sustainability/sn3011\%5B1\%5D.pdf.

[12] Struble, L., and Godfrey, J. 2004. "How Sustainable is Concrete?” In Proceedings of the International Workshop on Sustainable Development and Concrete Technology, Beijing, 201-1.

[13] Department for Environment, Food and Rural Affairs (UK), Carbon Conversion Factors: (a) HGV Delivery vehicles, Articulated (>3.5-33t), July 2015. (b) Liquid fuels, Diesel (100\% mineral diesel), July 2015. Accessed December 19, 2016. https://www.gov.uk/government/collections/governmentconversion-factors-for-company-reporting.

[14] Kent, R. 2009. "What's Your Process Energy
Fingerprint?” Plastics Technology (March).

[15] The French Environment and Energy Management Agency. 2007. "The $\mathrm{CO}_{2}$ Content of a $\mathrm{kWh}$ of Electricity.” Accessed December 19, 2016. http://www.agirpourlenvironnement.org/pdf/contenuCO2 longue.pdf.

[16] Spirinckx, C., Vanderreydt, I., Vercalsteren, A., Boonen, K., and Peeters, K. 2012. "Life Cycle Assessment of a PVC-U Solid Wall Sewer Pipe System (according to EN 1401), Final Third Party Report by VITO Commissioned by TEPPFA.” Accessed December 19, 2016. http://www.bureauleiding.nl/kennisdossier/Milieu\%20Pro duct\%20Verklaringen/EPD/PVC-solid\%20wall\%20sewer -Thirdpartyreport-March2012.pdf.

[17] Reade, L. 2011. "Reaching a Century: Polyolefin Developments.” AMI Pipe \& Profile Extrusion (March): 11.

[18] Breen, J. 2008. "Quality of PVC Sewage Pipes in the Netherlands.” TNO/Bureau Leiding. Accessed December 19 ,

2016. http://www.bureauleiding.nl/kennisdossier/Downloads\%2 0in\%20English/TNO\%20Quality\%20of\%20PVC\%20sew age\%20pipes\%20in\%20NL\%2002-04-08.pdf.

[19] DeArmitt, C., and Hancock, M. 2003. Filled Thermoplastics in Particulate-Filled Polymer Composites. Rothon, R. N., (Ed.) Rapra Technology Limited, Telford. 357-424.

[20] PPH1060-A Technical Data Sheet. Total Research \& Technology Feluy. www.polymers.total.com/pph1060.

[21] European Standard. December 2003. "EN 1916: Concrete Pipes and Fittings, Unreinforced, Steel Fibre and Reinforced."

[22] Spirinckx, C., Pieper, H., and Peeters, K. 2013. "Life Cycle Assessment of a PP Smooth Walled Monolayer Sewer Pipe System (according to EN 1852), Final Third Party Report by VITO Commissioned by TEPPFA.” Accessed December 19, 2016. https://static1.squarespace.com/static/54e49e84e4b062d0 77116c87/t/552fb67fe4b07f0b392507e5/1429190271006/ PP_smooth_wall_monolayer_sewer_Third_party_report_ 201308_-_Final.pdf.

[23] AMI Consulting. 2015. Gravity Pipes-the European Market 2015. Applied Market Information, Bristol. 